\title{
Cumulative Experience in Lymphovenous Anastomosis for Lymphedema Treatment: The Learning Curve Effect on the Overall Outcome
}

\author{
Nicolas Pereira, MD, MSc $\mathrm{MS}^{1,2,3}$ Yeon Hoon Lee, $\mathrm{MD}^{1}$ \\ Hyun Suk Suh, MD, $\mathrm{PhD}^{1}$ Jae Yong Jeon, $\mathrm{MD}, \mathrm{PhD}^{4}$
${ }^{1}$ Department of Plastic and Reconstructive Surgery, Asan Medical Center, University of Ulsan College of Medicine, Seoul, Republic of Korea
2 Department of Plastic Surgery and Burns, Hospital del Trabajador, Santiago, Chile
${ }^{3}$ Department of Plastic Surgery, Clínica Las Condes, Santiago, Chile
${ }^{4}$ Department of Rehabilitation Medicine, Asan Medical Center,
University of Ulsan College of Medicine, Seoul, Republic of Korea

Youngchul Suh, MD ${ }^{1}$ Dong Hoon Choi, MD ${ }^{1}$ Joon Pio (Jp) Hong, MD, PhD, MMM ${ }^{1}$

\author{
Address for correspondence Joon Pio Hong, MD, PhD, MMM, \\ Department of Plastic and Reconstructive Surgery, Asan Medical \\ Center, University of Ulsan College of Medicine, 388-1 Pungnap-dong, \\ Sonpa-gu, Seoul 138-736, Republic of Korea \\ (e-mail: joonphong@amc.seoul.kr).
}

J Reconstr Microsurg 2018;34:735-741.

Background The lymphovenous anastomosis (LVA) has become one of the treatment options for lymphedema. However, it is regarded as a difficult surgery that many young microsurgeons are reluctant to try. This report investigates the learning curve in regard to symptom improvement.

Methods This is a retrospective analysis performed in 33 consecutive lymphedema patients (38 extremities) who underwent only LVAs from August 2010 to February 2016. Surgical outcomes in regard to surgeon's experience were evaluated. The surgeons experience was divided into three groups: early group with less than 2 years, moderate with 2 to 4 years, and mature group with more than 4 years of experience. Results A total of 31 limbs (8/8 in upper extremity and 23/30 in lower extremity) showed improvement. When we compare volume change and recurrence of cellulitis with regard to surgeon's experience, there were no statistically significant differences. However, the mean time per LVA was significantly decreased as the experience increased over time $(p=0.017)$.

Conclusion LVA is an effective treatment option to reduce the volume in the affected limb and to improve symptoms involved. Regardless of the number and experience of the surgeons, cellulitis improves significantly after LVA. The experience of the surgeon does not significantly impact the positive outcome while proficiency increases with experience.
Lymphedema is a chronic and debilitating condition that has traditionally been seen as refractory or incurable. The clinical presentation is characterized by pain, limitation of daily activities, and difficulties in wearing normal clothes. Furthermore, lymphedema increases the risks of developing recurrent episodes of cellulitis in the affected extremity which frequently requires admission. ${ }^{1}$ In rare cases, chronic lymphedema is associated with increased incidence of malignancies such as lymphangiosarcoma (Stewart-Treves' syndrome), Kaposi sarcoma, and lymphoma. ${ }^{2}$ The disease may be primary, caused by agenesis or dysplasia of any component of the lymphatic network, or secondary, most commonly after trauma, surgical disruption, or recurrent infection. ${ }^{3}$ Most patients in developed countries present with lymphedema resulting from treatment received

November 2, 2017

accepted after revision

March 22, 2018

published online

May 3, 2018
Copyright $\odot 2018$ by Thieme Medical Publishers, Inc., 333 Seventh Avenue, New York, NY 10001, USA. Tel: +1(212) 584-4662.
DOI https://doi.org/

10.1055/s-0038-1648220. ISSN 0743-684X. 
of malignancy. Lymphedema is reported to occur in up to $49 \%$ of breast, $20 \%$ of gynecologic, $16 \%$ of melanoma, $10 \%$ of genitourinary, and $6 \%$ head and neck cancer patients after lymph node dissection with or without radiotherapy. ${ }^{4}$ Lymphedema after gynecologic surgery in ovarian cancer is present in $11.1 \%{ }^{5}$ and in $12.6 \%$ after cervical cancer radical surgery. ${ }^{6}$

In our center, all patients with lymphedema began with combined decongestive therapy (CDT). After a trained lymphedema therapist performs CDT, therapist or patients themselves should follow maintenance treatment. CDT consists in multiple components: manual lymph drainage/massage, compression bandaging, therapeutic exercise, and careful skin care. ${ }^{7-9}$ These approaches are frequently satisfactory enough but some patients' refractory to the CDTwill require some form of surgical intervention to ultimately reduce the lymphatic burden on their extremities.

The surgical approaches are based on an algorithm where physiological approach such as lymphovenous anastomosis (LVA) and vascularized lymph-node transfer (VLNT) are considered first. With the aid of new diagnostic tools, such as magnetic resonance lymphangiography (MRL), indocyanine green lymphography (ICG-L), Doppler venous flowmetry and manometry, and phleboscintigraphy and phlebography (in cases of phlebolymphedema angiodysplasia), it is now possible to consider the patient for LVA, VLNT, or combination of both. ${ }^{10-12}$ The LVA redirects excessive lymph fluid from the lymphedematous limb into the venous system by anastomosing lymphatic vessels to subdermal venules thus improves the symptom, while VLNT acts as a sponge to absorb the lymphatic fluid and stimulate neolymphangiogenesis improving the drainage from the extremity. ${ }^{13-18}$ When these physiological approaches are not indicated or have little effect, then symptomatic approaches are considered such as circumferential suction-assisted lipectomy or excisional surgical procedures. ${ }^{19-22}$

The LVA, VLNT, or combination of both is now becoming the primary approach for many patients with lymphedema. However, LVA is a relatively new microsurgical approach (supermicrosurgery) that needs special skills and tools, may be very challenging, and still has many questions to be answered. This study focused on authors' experience in LVA and to evaluate the LVA effect on symptom improvement especially cellulitis. Another question was to address the outcome of surgery based on surgeon's experience to provide an insight on whether accumulating experience impacts the overall outcome.

\section{Patients and Methods}

A retrospective analysis was performed in 33 consecutive lymphedema patients (38 extremities) with primary and secondary lymphedemas who underwent only LVAs from August 2010 to February 2016. This study was approved by the Institutional Review Board at the Asan Medical Center.

Relevant information was collected such as age, body mass index (BMI), lymphedema etiology, lymphedema duration, clinical stage, symptoms and their improvements, surgical data (operative time, number of LVAs, complications, etc.), follow-up time, and pre- and postoperative cellulitis episodes. To see the impact of experience on outcome, we divided the results based on years of surgeon's LVA supermicrosurgery experience: early experience-surgeons with less than 2 years of experience, moderate experience-surgeons with less than 4 years of experience, and mature experience-surgeons with more than 4 years of experience.

\section{Measurements}

All patients underwent to preoperative and postoperative measurements of both upper and lower limbs to serve as a baseline and as a control for response to therapy. Circumference measurements were taken with a tape measure at 5,10 , and $15 \mathrm{~cm}$ above and below the elbow/knee; before surgery; and after 1, 3, 6, and 12 months postoperative. Each volume segment was measured according to the formula of a truncated cone ( $\mathbf{- F i g . 1})^{23}$

$$
V=\pi \times h \times\left(R^{2}+r^{2}+R \times r\right) / 3
$$

where $\pi$ is a constant; $h$ is the height; $R$ is the radius on base; and $r$ is the radius on top.

Using this formula, we were able to estimate the volume of part of the limb. These estimations were analyzed to evaluate lymphedema improvement after surgical treatment. In patients with unilateral lymphedema, measurements of the nonaffected limb allowed to compare with the lymphedematous limb and determination of the percentage of excess volume (PEV) of the affected limb (PEV = volume of affected limb - volume of unaffected contralateral limb/volume of unaffected contralateral limb). The reduction excess volume (REV) between preoperative and postoperative was calculated in unilateral cases $(\mathrm{REV}=$ [preoperative PEV - postoperative $\mathrm{PEV}]$ /preoperative PEV). In bilateral cases, difference of preoperative and postoperative volume and volume percentage change was calculated (VPC $=$ [postoperative volume - preoperative volume]/preoperative volume).
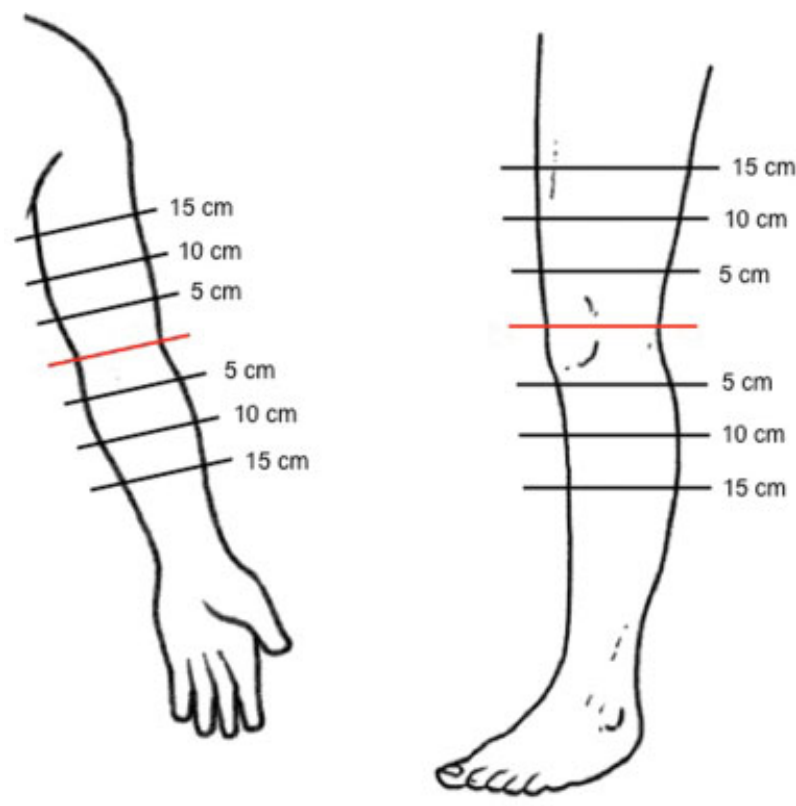

Fig. 1 Circumference measurements sites in upper extremities and lower extremities. 


\section{Surgical Technique}

Approaches were based on preoperative MRL and ICG-L. Then, a 3-cm incision was made to obtain subdermal/subcutaneous venules as the proximal recipient of lymphatic vessels. The LVA technique was not indicated in cases where lymphostatic disease was associated with venous flow impairment (varices, venous hypertension, and valvular incontinence). LVA was performed with 10-0 or 11-0 suture. Usually, a three-level approach was used in the lower extremity, which involves the ankle, knee, and groin region. The upper extremity involves two levels at wrist and elbow in addition with scar release on the axilla region. After the procedure, the skin is closed and minimal pressure dressing was applied.

\section{Postoperative Care}

After the operation, splints were applied for immobilization of operated sites. Patients stayed hospitalized for 3 to 5 days after operation. Absolute circumference of operated limbs was measured daily on postoperative days 1 to 5 . Postoperative rehabilitation protocol was followed where the patients started their CDT 2 weeks after surgery.

\section{Statistical Analysis}

Wilcoxon's signed-rank test was performed to compare preoperative and postoperative volume and percentage of excess of volume. Kruskal-Wallis' test was performed to compare these results in the three periods of time. SAS software version 9.4 (SAS Institute, Cary, NC) was used for statistical analysis.

\section{Results}

A total of four surgeons were evaluated. LVA was performed in 8 upper extremities ( 6 left and 2 right) and 30 lower extremities ( 8 left, 12 right, and 5 bilateral). The upper extremity lymphedema was secondary to breast cancer treatment in $100 \%$ of the cases. Lower extremity lymphedema was primary in 13 extremities (43.3\%), secondary to gynecologic cancer treatment in 14 extremities (46.6\%), and trauma in 3 extremities (9.9\%). All patients were selected with the same criteria among the surgeons.

\section{Upper Extremity}

The mean age of the patients was 48.9 years (range: $35-59$ ). The mean lymphedema duration was 4.61 years (range: 2-9.25). The mean BMI was $23.34 \mathrm{~kg} / \mathrm{m}^{2}$ (range: 19.91-29.95). The mean preoperative volume of the affected upper limb was $1,204.6 \mathrm{~mL}$ (range: $900.8-1,535.2$ ) and the mean preoperative PEV between the affected and the healthy limb was $26.73 \%$ (range: 8.28-47.4\%). Patient's mean follow-up time was 27.4 months (range: $3-84$ ).

Symptoms improved in $100 \%$ of the patients (eight cases). Postoperative mean volume measurement was $1,054.5 \mathrm{~mL}$ (range: 771-1,217) and postoperative mean PEV was $11.55 \%$ (range: -11.75 to 39.02 ) demonstrating a statistically significant quantitative improvement in both parameters $(p=0.012)$. The reduction of excess volume after LVA was 64.97 (- Fig. 2).

Mean operative time was 257.5 minutes (range: 163-354). Mean number of LVA per upper extremity was 3.75 (range: 1-6), so mean time per LVA was 96.1 (range: 27.1-261) minutes. Preoperative mean number of cellulitis episodes per year was 1.3 (range: $0-3$ ). It decreased dramatically to 0 episode after LVA (-Table 1).

When we compared volume change with regard to surgeon's experience, there were no statistically significant differences. However, the mean time per LVA significantly decreased as the experience increased for surgeons.

\section{Lower Extremity}

The mean age of the patients was 44.1 years (range: 6-72). The mean lymphedema duration was 11.025 years (range: $1-45$ ). The mean BMI was $25.18 \mathrm{~kg} / \mathrm{m}^{2}$ (range: 16.41-37.99). In

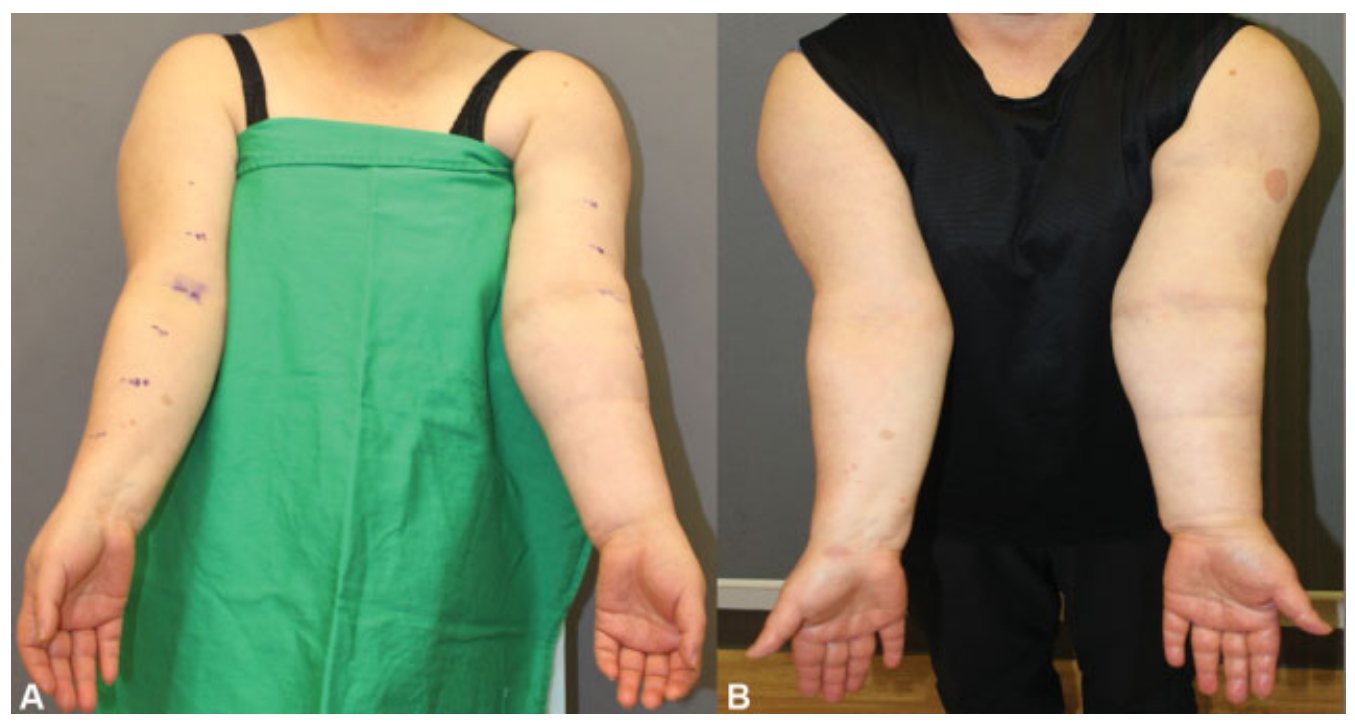

Fig. 2 (A, B) Preoperative and 7 years follow-up postoperative pictures of a 59-year-old female patient with left unilateral upper extremity lymphedema secondary to breast cancer treatment. Preoperatively she had 1,535.25 mL and postoperatively $1,109.05 \mathrm{~mL}$ on her left arm, with an absolute volume decrease of $426.2 \mathrm{~mL}$. 
Table 1 Results of upper extremity lymphedema patients

\begin{tabular}{|c|c|c|}
\hline Characteristics & No. & Range or \% \\
\hline Mean age at surgery $(y)$ & 48.9 & $(35-59)$ \\
\hline Mean BMI $\left(\mathrm{kg} / \mathrm{m}^{2}\right)$ & 23.34 & $(19.91-29.95)$ \\
\hline $\begin{array}{l}\text { Mean lymphedema } \\
\text { duration }(y)\end{array}$ & 4.61 & $(2-9.25)$ \\
\hline \multirow[t]{3}{*}{ Lymphedema stage } & 2 & $25 \%$ \\
\hline & II & $62.5 \%$ \\
\hline & III & $12.5 \%$ \\
\hline \multirow[t]{2}{*}{ Side } & Left & $75 \%$ \\
\hline & \begin{tabular}{l|l} 
Right & 2
\end{tabular} & $25 \%$ \\
\hline $\begin{array}{l}\text { Mean operative } \\
\text { time (min) }\end{array}$ & 257.5 & $(163-354)$ \\
\hline Mean number of LVA & 3.75 & $(1-6)$ \\
\hline Mean follow up (mo) & 27.4 & $(3-84)$ \\
\hline Symptoms improvement & 8 & $100 \%$ \\
\hline Volume & Mean & \\
\hline $\begin{array}{l}\text { Mean preoperative } \\
\text { volume }(\mathrm{mL})\end{array}$ & $1,204.66$ & $(900.84-1,535.25)$ \\
\hline $\begin{array}{l}\text { Mean postoperative } \\
\text { volume }(\mathrm{mL})\end{array}$ & $1,054.52$ & $(771-1,217.04)$ \\
\hline $\begin{array}{l}\text { Percentage of } \\
\text { volume excess }\end{array}$ & Mean & \\
\hline $\begin{array}{l}\text { Mean preoperative } \\
\text { volume excess (\%) }\end{array}$ & 26.73 & $(8.28-47.4)$ \\
\hline $\begin{array}{l}\text { Mean postoperative } \\
\text { volume excess (\%) }\end{array}$ & 11.55 & $(-11.75-39.02)$ \\
\hline $\begin{array}{l}\text { Reduction of excess } \\
\text { volume (\%) }\end{array}$ & 64.97 & $(5.02-153.02)$ \\
\hline Cellulitis & Mean & \\
\hline $\begin{array}{l}\text { Number of episodes } \\
\text { per year preoperative }\end{array}$ & 1.3 & $(0-3)$ \\
\hline $\begin{array}{l}\text { Number of episodes } \\
\text { per year postoperative }\end{array}$ & 0 & 0 \\
\hline
\end{tabular}

Abbreviations: BMI, body mass index; LVA, lymphovenous anastomosis.

unilateral cases, the mean preoperative volume of the affected lower limb was 2,795.2 $\mathrm{mL}$ (range: 1,485.1-4,935.2 mL) and the mean preoperative PEV between the affected and the healthy limb was $33.58 \%$ (range: $-22.63-92.98 \%$ ). In bilateral cases, the mean preoperative volume of the affected lower limb was $2,876.3 \mathrm{~mL}$ (range: 2,226.2-4,263.1 mL). Patient's mean follow-up time was 16.6 months (range: $3-48$ ).

Symptoms improved in $77 \%$ of the cases ( 23 extremities). In unilateral cases, postoperative mean volume measurement was $2,605.2 \mathrm{~mL}$ (range: $1,212-4,145.9 \mathrm{~mL}$ ) and postoperative mean PEV was 25.23\% (range: -12.1-104.08\%) demonstrating a statistically significant quantitative improvement in the first parameter ( $p=0.03$ and $p=0.061$, respectively). In bilateral cases, postoperative mean volume measurement was $2,600.4$ $\mathrm{mL}$ (range: $2,059.8-3,125.8 \mathrm{~mL}$ ) demonstrating a statistically significant quantitative improvement $(p=0.013)$. The reduction of excess volume after LVA was $39.81 \%$ ( - Fig. 3 ).
Mean operative time was 213.7 minutes (range: 81-543). Mean number of LVA per lower extremity was 2.3 (range: 1-7); therefore, mean time per LVAwas 116.8 (range: 38.7-274) minutes. Preoperative mean number of cellulitis episodes per year was 2.6 (range: $0-10$ ). It decreased dramatically to a mean number of episodes of 0.12 after LVA (range: $0-1$ ) (-Table 2).

When we compare volume change with regard to surgeon's experience, there were no statistically significant differences. However, the mean time per LVA significantly decreased as the surgeon's experience increased over time $(p=0.017)(-$ Fig. 4).

\section{Discussion}

Lymphedema is a progressive and debilitating condition associated with dysfunction of the lymphatic system. ${ }^{24}$ The performance of LVA in patients affected by upper or lower limb lymphedema achieved a significant reduction in the volume of the treated limb with reported improvement of symptoms such as less effort in lifting extremity, less discomfort, increased range of motion, and decreased episodes of cellulitis. Episodes of cellulitis are especially severe as it frequently needs admission despite the use of prophylactic antibiotics which has been the mainstream treatment. ${ }^{25-27}$ Definitive prevention of cellulitis from lymphedema remains to be seen. Among the expected outcomes of LVA, decrease in frequency of cellulitis episodes and its severity is very important since it can be even a life-threatening condition. In a cohort of 95 patients, Mihara et al evaluated cellulitis episodes and found a statistically significant decrease in frequency in patients with upper or lower limb lymphedema comparing before and after LVAs. ${ }^{28}$ Our patients experienced a dramatic decrease in number of episodes of cellulitis after LVA from 1.3 (range: $0-3$ ) episodes per year to 0 episode in the upper extremity and 2.6 (range: $0-10$ ) episodes per year to 0.12 episodes in lower extremity reducing the need for prophylactic antibiotics and improving the quality of life and possibly preventing a vicious cycle of aggravation caused by recurrent cellulitis. This was an interesting finding as most of the LVA despite the number of anastomosis or experience of the surgeon did not play a role in overall outcome of cellulitis. Furthermore, improvement in cellulitis recurrence was noted even in some patients who did not have a significant improvement in volume reduction. Thus, a minimal number of LVA may limit the formation of cellulitis from lymphedema or even may be able to prevent it from recurring.

Outcome evaluation methods following LVA may vary depending on the institution. Objective analysis using limb volume differences between normal and affected limbs in unilateral cases appear to be the most adequate. We performed preoperative and postoperative measurements of both limbs to serve as a baseline and as a control for response to therapy. We calculated the volume using the truncated cone formula and the PEV as previously reported. ${ }^{23}$ When lymphedema is bilateral, there is a limitation because we can just compare the improvements within the same limb without having a reference unaffected limb; therefore, body weight changes can interfere in the proper follow-up assessment. 


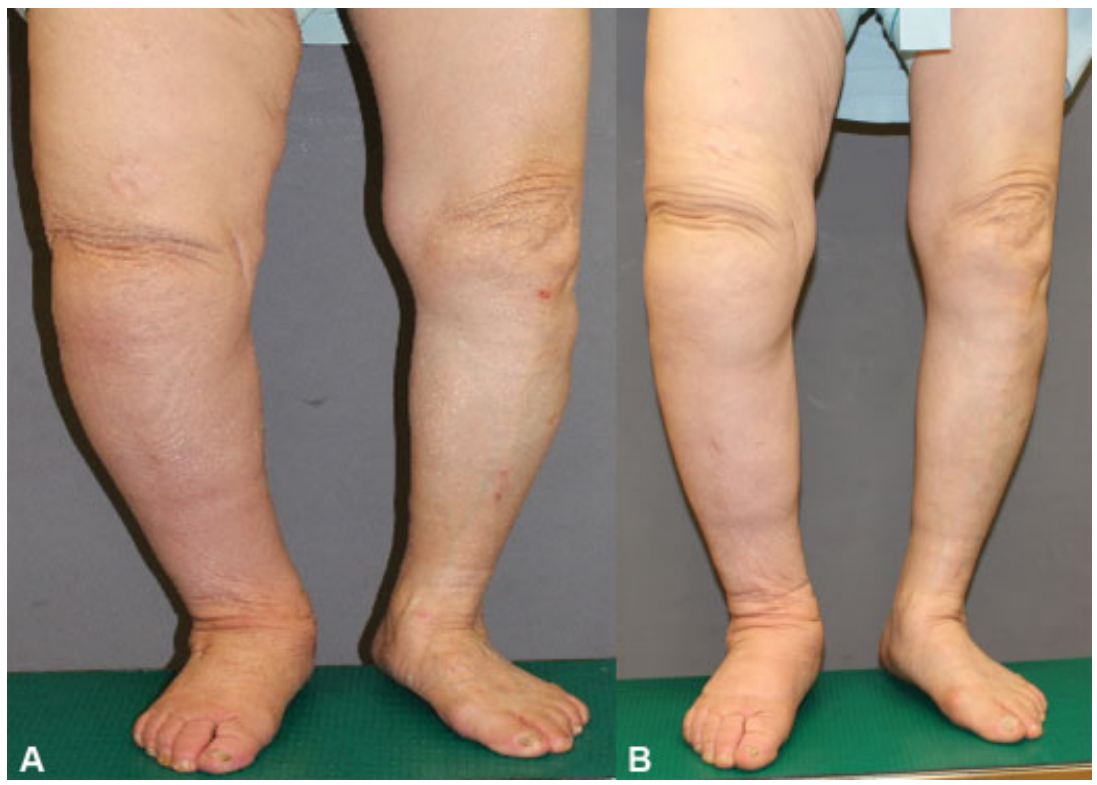

Fig. 3 (A, B) Preoperative and 4 years follow-up postoperative pictures of a 72-year-old female patient with right unilateral lower extremity primary lymphedema. Preoperatively she had $4,074.25 \mathrm{~mL}$ and postoperatively $2,789.6 \mathrm{~mL}$ on her left lower limb, with an absolute volume decrease of $1,284.65 \mathrm{~mL}$. Number of episodes of cellulitis decreased dramatically from 3 to 4 per year to 0 episode after LVA. LVA, lymphovenous anastomosis.

Koshima et al reported their experience with 18 patients (aged: 38-73 years) with upper extremity lymphedema who underwent supermicrosurgical LVA. ${ }^{29}$ The average duration of upper extremity lymphedema was 7.2 years (range: 11 months-22 years). The patients were followed up for an average of 2.6 years (range: $1-10$ years), and a decrease in the circumference in average $4.5 \mathrm{~cm}(0-8.5 \mathrm{~cm})$ was obtained. The average decrease rate in the circumference was $45.2 \%$ of the preoperative excess length. Chang et al found in a prospective study in 100 consecutive patients that LVA can be effective in reducing lymphedema severity. ${ }^{30}$ In patients with early-stage lymphedema, a mean volume differential reduction of $61 \%$ at 12 months after LVA was noted. In patients with late-stage lymphedema with few functioning lymphatic vessels and significant tissue fibrosis, the results were not as impressive with only a $17 \%$ mean volume differential reduction at 12 months after LVA. We also considered it necessary to perform a different analysis for upper and lower extremity lymphedema. The behavior can be different over time as lower limb lymphedema treatment may be more complicated due to the dependent position of the leg, the larger volume of the lower limb, and the effects of ambulation. In our series, lower extremity lymphedema stages were more severe compared with the upper extremity lymphedema stages. Our upper limb improvements were better than lower limb, but in both cases, the decrease of postoperative volume was statistically significant. Although the results showed significant reduction, large portion of the patients did not reach the normal appearance compared with the unaffected arm. This was due to the fact that the patients reviewed in this study, with the exception of two upper limbs and one lower limb, were all advanced stages of lymphedema. The approach has now moved to detect nonresponders to CDT who are still in the early stages of lymphedema to increase their chance for full recovery. ${ }^{31,32}$
It has been reported that the higher number of LVA sites performed during surgery correlates to better volume reduction. ${ }^{32}$ We agree with this approach but the time and effort consumed to find the lymphatic vessels cannot be overlooked. Report suggesting that only one functional LVA could be enough to obtain satisfactory outcomes has nudged us to move to a simpler approach. ${ }^{33}$ The authors have simplified the approach to identify relatively constant lymphatic vessels that are easier to find. These lymphatic vessels are usually easily identifiable at wrist and elbow for the arm and foot/ankle, knee, and groin for the lower extremity. Frequently, the scar formed after dissection of lymph nodes on the axilla region requires scar removal to improve the continuity of the lymphatic flow located in the fat. The strategy to have a three-level approach has allowed us to have reasonable results even for beginners as shown in this study.

The fear to start a lymphedema practice using LVA can be challenging and daunting for beginners. An interesting finding in this study was the consistent positive result regardless of the years of experience implying that although supermicrosurgical skills are needed, beginners can perform LVA achieving good results. The approach to anatomically constant and relatively large lymphatic vessels allows increased chance for successful outcome. As the surgeon gains experience, operating time per LVA decreased significantly. This finding was evident in our review as one surgeon's experience passed through all the phase of early, moderate, and mature experience. However, if one questions the quality of the outcome, it was very difficult to determine it as each patient progress differs due to various factors and may remain as a limitation of this study. We also realize that individual's given innate hand skills may play a role. Nevertheless, most patients showed reduction of volume despite 
Table 2 Results of lower extremity lymphedema patients

\begin{tabular}{|c|c|c|c|}
\hline Characteristics & \multicolumn{2}{|l|}{ No. } & Range or \% \\
\hline $\begin{array}{l}\text { Mean age at } \\
\text { surgery }(y)\end{array}$ & \multicolumn{2}{|l|}{44.1} & $(6-72)$ \\
\hline Mean BMI $\left(\mathrm{kg} / \mathrm{m}^{2}\right)$ & \multicolumn{2}{|l|}{25.18} & $(16.41-37.99)$ \\
\hline $\begin{array}{l}\text { Mean lymphedema } \\
\text { duration (y) }\end{array}$ & \multicolumn{2}{|l|}{11.025} & $(1-45)$ \\
\hline \multirow[t]{3}{*}{ Lymphedema stage } & 1 & 1 & $3.3 \%$ \\
\hline & II & 19 & $63.3 \%$ \\
\hline & III & 10 & $33.3 \%$ \\
\hline \multirow[t]{3}{*}{ Side } & Left & 8 & $26.6 \%$ \\
\hline & Right & 12 & $40 \%$ \\
\hline & Bilateral & 5 & $33.3 \%$ \\
\hline $\begin{array}{l}\text { Mean operative } \\
\text { time (min) }\end{array}$ & \multicolumn{2}{|l|}{213.7} & $(81-543)$ \\
\hline Mean number of LVA & \multicolumn{2}{|l|}{2.3} & $(1-7)$ \\
\hline Mean follow up (mo) & \multicolumn{2}{|l|}{16.6} & $(3-48)$ \\
\hline $\begin{array}{l}\text { Symptoms } \\
\text { improvement }\end{array}$ & \multicolumn{2}{|l|}{23} & $92 \%$ \\
\hline Volume & \multicolumn{2}{|l|}{ Mean } & \\
\hline \multicolumn{4}{|l|}{ Unilateral } \\
\hline $\begin{array}{l}\text { Mean preoperative } \\
\text { volume }(\mathrm{mL})\end{array}$ & \multicolumn{2}{|l|}{$2,795.23$} & $(1,485.15-4,935.25)$ \\
\hline $\begin{array}{l}\text { Mean postoperative } \\
\text { volume }(\mathrm{mL})\end{array}$ & \multicolumn{2}{|l|}{$2,605.28$} & $(1,212.07-4,145.97)$ \\
\hline \multicolumn{4}{|l|}{ Bilateral } \\
\hline $\begin{array}{l}\text { Mean preoperative } \\
\text { volume }(\mathrm{mL})\end{array}$ & \multicolumn{2}{|l|}{$2,876.31$} & $(2,226.25-4,263.11)$ \\
\hline $\begin{array}{l}\text { Mean postoperative } \\
\text { volume }(\mathrm{mL})\end{array}$ & \multicolumn{2}{|l|}{$2,600.41$} & $(2,059.87-3,125.82)$ \\
\hline $\begin{array}{l}\text { Percentage of } \\
\text { volume excess }\end{array}$ & \multicolumn{2}{|l|}{ Mean } & \\
\hline $\begin{array}{l}\text { Mean preoperative } \\
\text { volume excess (\%) }\end{array}$ & \multicolumn{2}{|l|}{33.57} & $(22.63-92.98)$ \\
\hline $\begin{array}{l}\text { Mean postoperative } \\
\text { volume excess (\%) }\end{array}$ & \multicolumn{2}{|l|}{25.23} & $(-12.10$ to 104.08$)$ \\
\hline $\begin{array}{l}\text { Reduction of excess } \\
\text { volume }(\%)\end{array}$ & \multicolumn{2}{|l|}{39.81} & $(-85.93$ to 208.79$)$ \\
\hline Cellulitis & \multicolumn{2}{|l|}{ Mean } & \\
\hline $\begin{array}{l}\text { Number of episodes } \\
\text { per year preoperative }\end{array}$ & \multicolumn{2}{|l|}{2.6} & $(0-10)$ \\
\hline $\begin{array}{l}\text { Number of episodes } \\
\text { per year postoperative }\end{array}$ & \multicolumn{2}{|l|}{0.12} & $(0-1)$ \\
\hline
\end{tabular}

Abbreviations: BMI, body mass index; LVA, lymphovenous anastomosis.

the experience of the surgeon. The authors encourage microsurgeons who do not perform lymphatic surgery to dare to perform LVA because it is a reliable technique with good results, which allows the treatment of many patients affected by this disease.

\section{Conclusion}

Lymphovenous anastomosis is an effective treatment option to reduce the volume in the affected limb and to improve symptoms involved. Regardless of the number and experi-
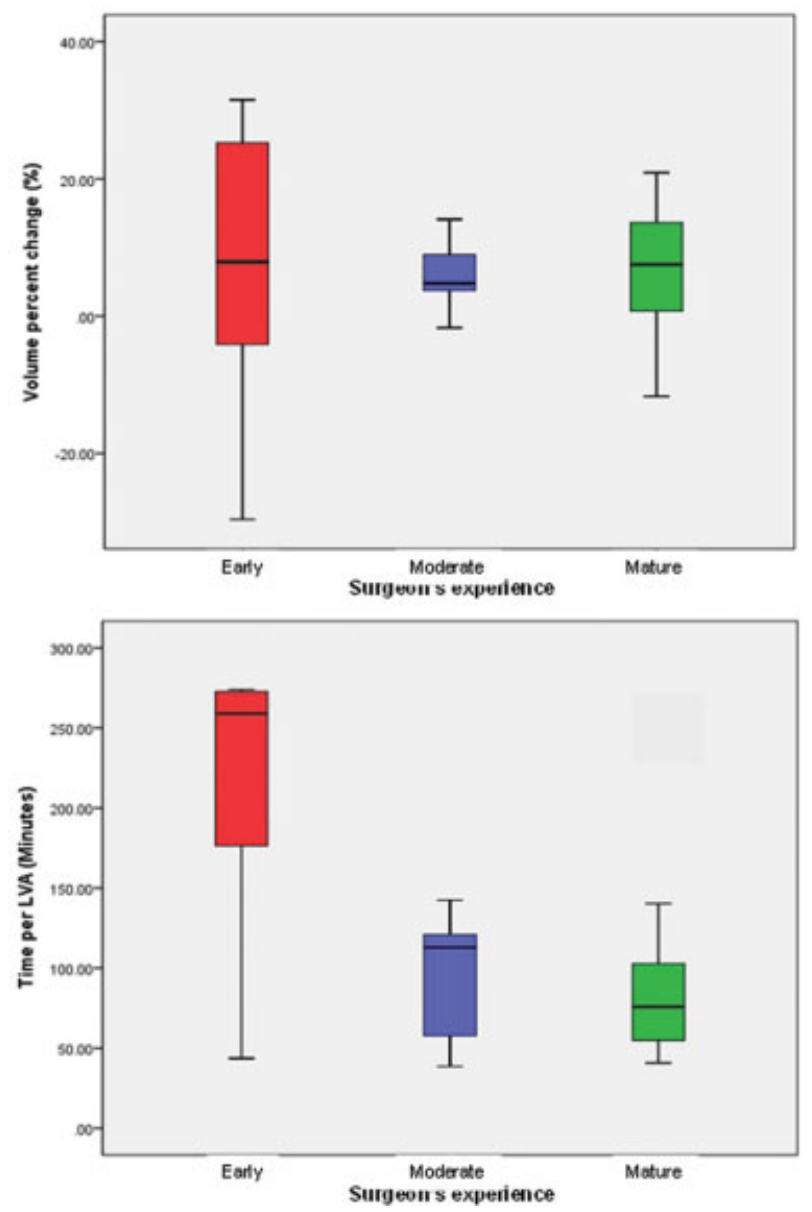

Fig. 4 Lower extremity lymphedema with regard to surgeon's experience: early experience ( $<2$ years), moderate experience ( $<4$ years), and mature experience ( $>4$ years). (Above) Volume percentage change with regard to surgeon's experience, with no statistically significant difference showing consistent results. (Below), Mean time per LVA decreases as surgeon's experience increases, with statistically significant difference $(p=0.017)$. LVA, lymphovenous anastomosis.

ence of the surgeons, cellulitis improves significantly after LVA. The experience of the surgeon does not significantly impact the positive outcome, while proficiency increases with experience.

\section{Conflict of Interest}

None.

\section{References}

1 Basta MN, Gao LL, Wu LC. Operative treatment of peripheral lymphedema: a systematic meta-analysis of the efficacy and safety of lymphovenous microsurgery and tissue transplantation. Plast Reconstr Surg 2014;133(04):905-913

2 Ruocco V, Schwartz RA, Ruocco E. Lymphedema: an immunologically vulnerable site for development of neoplasms. J Am Acad Dermatol 2002;47(01):124-127

3 Garfein ES, Borud LJ, Warren AG, Slavin SA. Learning from a lymphedema clinic: an algorithm for the management of localized swelling. Plast Reconstr Surg 2008;121(02):521-528 
4 Cormier JN, Askew RL, Mungovan KS, Xing Y, Ross MI, Armer JM. Lymphedema beyond breast cancer: a systematic review and meta-analysis of cancer-related secondary lymphedema. Cancer 2010;116(22):5138-5149

5 Ki EY, Park JS, Lee KH, Hur SY. Incidence and risk factors of lower extremity lymphedema after gynecologic surgery in ovarian cancer. Int J Gynecol Cancer 2016;26(07):1327-1332

$6 \mathrm{Kim} \mathrm{JH}$, Choi JH, Ki EY, et al. Incidence and risk factors of lowerextremity lymphedema after radical surgery with or without adjuvant radiotherapy in patients with FIGO stage I to stage IIA cervical cancer. Int J Gynecol Cancer 2012;22(04):686-691

7 International Society of Lymphology. The diagnosis and treatment of peripheral lymphedema. 2009 Concensus Document of the International Society of Lymphology. Lymphology 2009;42 (02):51-60

8 Lerner R. Complete decongestive physiotherapy and the Lerner Lymphedema Services Academy of Lymphatic Studies (the Lerner School). Cancer 1998;83(12, Suppl American):2861-2863

9 DiSipio T, Rye S, Newman B, Hayes S. Incidence of unilateral arm lymphoedema after breast cancer: a systematic review and metaanalysis. Lancet Oncol 2013;14(06):500-515

10 Warren AG, Brorson H, Borud LJ, Slavin SA. Lymphedema: a comprehensive review. Ann Plast Surg 2007;59(04):464-472

11 Chen WF, Zhao H, Yamamoto T, Hara H, Ding J. Indocyanine green lymphographic evidence of surgical efficacy following microsurgical and supermicrosurgical lymphedema reconstructions. J Reconstr Microsurg 2016;32(09):688-698

12 Narushima M, Yamamoto T, Ogata F, Yoshimatsu H, Mihara M, Koshima I. Indocyanine green lymphography findings in limb lymphedema. J Reconstr Microsurg 2016;32(01):72-79

13 Campisi C, Davini D, Bellini C, et al. Lymphatic microsurgery for the treatment of lymphedema. Microsurgery 2006;26(01):65-69

14 Chang DW. Lymphaticovenular bypass for lymphedema management in breast cancer patients: a prospective study. Plast Reconstr Surg 2010;126(03):752-758

15 Cheng MH, Huang JJ, Wu CW, et al. The mechanism of vascularized lymph node transfer for lymphedema: natural lymphaticovenous drainage. Plast Reconstr Surg 2014;133(02):192e-198e

16 Patel KM, Lin CY, Cheng MH. From theory to evidence: long-term evaluation of the mechanism of action and flap integration of distal vascularized lymph node transfers. J Reconstr Microsurg 2015;31(01):26-30

17 Carl HM, Walia G, Bello R, et al. Systematic review of the surgical treatment of extremity lymphedema. J Reconstr Microsurg 2017; 33(06):412-425

18 Sosin M, Yin C, Poysophon P, Patel KM. Understanding the concepts and physiologic principles of lymphatic microsurgery. J Reconstr Microsurg 2016;32(08):571-579
19 Damstra RJ, Voesten HG, Klinkert P, Brorson H. Circumferential suction-assisted lipectomy for lymphoedema after surgery for breast cancer. Br J Surg 2009;96(08):859-864

20 Charles R. The surgical technique and operative treatment of elephatiasis of the generative organs based on a series of 140 consecutive successful cases. Ind Med Gaz 1901;36:84

21 Thompson $\mathrm{N}$. The surgical treatment of chronic lymphoedema of the extremities. Surg Clin North Am 1967;47(02):445-503

22 Servelle M. La lymphangiectomie superficielle totale. Traitement chirurgical de l'éléphantiasis. Rev Chir 1947;85(9-10):294

23 Brorson H, Höijer P. Standardised measurements used to order compression garments can be used to calculate arm volumes to evaluate lymphoedema treatment. J Plast Surg Hand Surg 2012;46 (06):410-415

24 Penha TR, Botter B, Heuts EM, Voogd AC, von Meyenfeldt MF, van der Hulst RR. Quality of life in patients with breast cancer-related lymphedema and reconstructive breast surgery. J Reconstr Microsurg 2016;32(06):484-490

25 Simon MS, Cody RL. Cellulitis after axillary lymph node dissection for carcinoma of the breast. Am J Med 1992;93(05):543-548

26 Olszewski WL, Jamal S, Manokaran G, Lukomska B, Kubicka U. Skin changes in filarial and non-filarial lymphoedema of the lower extremities. Trop Med Parasitol 1993;44(01):40-44

27 Vignes S, Dupuy A. Recurrence of lymphoedema-associated cellulitis (erysipelas) under prophylactic antibiotherapy: a retrospective cohort study. J Eur Acad Dermatol Venereol 2006;20(07): 818-822

28 Mihara M, Hara H, Furniss D, et al. Lymphaticovenular anastomosis to prevent cellulitis associated with lymphoedema. $\mathrm{Br} \mathrm{J}$ Surg 2014;101(11):1391-1396

29 Koshima I, Inagawa K, Urushibara K, Moriguchi T. Supermicrosurgical lymphaticovenular anastomosis for the treatment of lymphedema in the upper extremities. J Reconstr Microsurg 2000;16(06):437-442

30 Chang DW, Suami H, Skoracki R. A prospective analysis of 100 consecutive lymphovenous bypass cases for treatment of extremity lymphedema. Plast Reconstr Surg 2013;132(05):1305-1314

31 Akita S, Mitsukawa N, Kuriyama M, et al. Suitable therapy options for sub-clinical and early-stage lymphoedema patients. J Plast Reconstr Aesthet Surg 2014;67(04):520-525

32 Mihara M, Hara H, Tange S, et al. Multisite lymphaticovenular bypass using supermicrosurgery technique for lymphedema management in lower lymphedema cases. Plast Reconstr Surg 2016;138(01):262-272

33 Seki Y, Yamamoto T, Yoshimatsu H, et al. The superior-edge-ofthe-knee incision method in lymphaticovenular anastomosis for lower extremity lymphedema. Plast Reconstr Surg 2015;136(05): $665 e-675 e$ 